\title{
Raising HDL cholesterol with low-dose nicotinic acid and bezafibrate: preliminary experience
}

\author{
Myron H. Luria and Dan Sapoznikov
}

Department of Cardiology, Hadassah University Hospital, PO Box 12000, 91120 Jerusalem, Israel

Summary: Nicotinic acid is an effective agent for elevating HDL cholesterol but is limited by side effects. In order to improve tolerance and lipid levels, we combined low-dose nicotinic acid with bezafibrate. We gave low-dose (mean $435 \mathrm{mg} /$ day) nicotinic acid to 37 patients with low HDL cholesterol, bezafibrate (mean $476 \mathrm{mg} /$ day) to 58 patients with elevated total cholesterol and both agents (mean nicotinic acid $435 \mathrm{mg} /$ day and bezafibrate $512 \mathrm{mg} /$ day) to 25 patients with low HDL cholesterol and elevated total cholesterol. A total of 53 additional patients were followed as controls. Three intervals of treatment were studied: $0-6,6-12$ and $>12$ months.

The combination of drugs resulted in significant $(P<0.05)$ percentage changes in total cholesterol, triglycerides and total/HDL cholesterol compared to nicotinic acid alone and significant $(P<0.04)$ percentage changes in HDL cholesterol compared to bezafibrate alone. It is concluded that low doses of nicotinic acid may result in significant changes in HDL cholesterol; when combined with bezafibrate significant alterations in total cholesterol, triglycerides and total/HDL cholesterol also result.

\section{Introduction}

There is increasing emphasis on the importance of high-density lipoprotein (HDL) cholesterol to the atherosclerotic process. ${ }^{1-6}$ Nicotinic acid is probably the most effective present agent for elevating HDL cholesterol but unfortunately the side effect of flushing has limited its usefulness. ${ }^{7}$ An alternate group of drugs which may raise HDL cholesterol are the fibric acid derivatives. These drugs also lower total cholesterol and triglycerides. ${ }^{8,9} \mathrm{We}$ have, therefore, questioned whether by combining low-dose nicotinic acid with a fibrate drug such as bezafibrate, we might obtain a consistent HDL elevation, better tolerance of nicotinic acid and significant reductions in total cholesterol and triglycerides. In the present study we report our experience with low-dose nicotinic acid and bezafibrate in a group of 173 patients attending our cardiac clinic.

\section{Methods}

We have employed nicotinic acid in the Hadassah Cardiac Clinic since 1988 with the following guidelines. Beginning with $50 \mathrm{mg}$ nicotinic acid per day, patients with low HDL cholesterol ( $\leqslant 1.09 \mathrm{mmol} / \mathrm{l}$ ) were given nicotinic acid in increasing doses to a point where they no longer wished to proceed to a

Correspondence: Myron H. Luria, M.D.

Accepted: 25 September 1992 higher dose, generally because of the side effect $\mathscr{f} \oplus$ flushing. This sensitivity, consisting of upper trun and facial flushing, redness and prickly itching generally felt to be due to release of endogenous prostaglandins. ${ }^{10}$ Bezafibrate was given to patients with total cholesterol levels $\geqslant 6.22 \mathrm{mmol} / \mathrm{l}$ in conventional doses of $200 \mathrm{mg}$ two or three times per $\stackrel{\varnothing}{\varrho}$ day. Patients with both low HDL cholesterol and $\overrightarrow{\vec{O}}$ high total cholesterol were given both medications. Except for one patient taking nicotinic acid with $\bar{P}$ persistently elevated alkaline phosphatase levels, no abnormal liver function tests, renal function 0 tests or significantly elevated blood sugar com- 3 . pared to baseline were noted in any of the drug- $\dot{\sigma}$ treated patients. In order to observe the consistency of lipid values, a concomitant group of cardiac $\bigcirc$ patients who did not meet these guidelines were $₹$ included as controls. Patients in all categories were 울 given general instruction in a low animal fat diet. $\supset$

Total cholesterol, HDL cholesterol and triglycerides were determined by enzymatic methods ${ }^{11}$ N every 3-4 months. Patients also often received 5 low-dose aspirin, calcium-channel blockers and $\mathcal{N}^{\circ}$ dipyridamole. These medications were maintained $N_{\omega}$ without modification throughout the follow-up period. Beta adrenergic blocking agents were taken 0

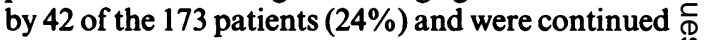
unchanged throughout the follow-up period.

For comparison of values within the same $\underline{T}$ therapeutic group before and during therapy, we $\stackrel{\circ}{\mathcal{D}}$

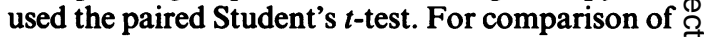
lipid values between different therapeutic groups, $\stackrel{\mathbb{Q}}{\varrho}$ 
we used the two-tailed unpaired Student's $t$-test. When a $P$ value as an indication of significance is noted for several relationships, the least significant value below $P \leqslant 0.05$ is specified.

\section{Results}

General data including mean drug doses, age, sex and average number of months followed in each of three time periods are indicated in Table I. The number of patients per interval fluctuate since patients were followed for varying lengths of time. Lipid results are averaged in Table II for baseline and three time intervals.

Because of the differing baseline values which were expected as a result of the clinical guidelines, we also analysed the data according to percentage change (Figure 1). When compared to the control group, low-dose nicotinic acid significantly $(P<0.02)$ increased the percentage change of HDL cholesterol and reduced the ratio total/HDL cholesterol at all three time intervals; bezafibrate significantly $(P<0.03)$ altered the percentage change of total cholesterol, HDL cholesterol and triglycerides at all three time intervals; and nicotinic acid plus bezafibrate significantly $(P<0.02)$ altered the percentage change of HDL cholesterol, triglycerides and the ratio total/HDL cholesterol at all three intervals, percentage change of total cholesterol being significantly $(P<0.03)$ altered only for the first two intervals.

When the bezafibrate group is compared to the nicotinic acid group, the percentage change in total cholesterol and triglycerides is significant $(P<0.05)$ with no significant changes evident in percentage change of HDL cholesterol.

Of consequence are the findings relating the percentage change in lipids for the combination of drugs versus each drug individually. The combination resulted in significant $(P<0.05)$ alterations compared to nicotinic acid alone in all three intervals for the percentage change of ratio total/ HDL cholesterol and triglycerides, with percentage change of total cholesterol being significantly $(P<0.04)$ altered only for the first two intervals. When the combination is compared to bezafibrate alone, significant $(P<0.04)$ percentage changes in HDL cholesterol for all three intervals are present and the percentage change in the ratio is significantly $(P<0.02)$ altered only for the first interval. Thus the combination significantly alters the percentage changes of total cholesterol and triglycerides compared to nicotinic acid alone and of HDL cholesterol compared to bezafibrate alone.

\section{Discussion}

The results of this study indicate that in a clinically selected population of cardiac patients, low doses of nicotinic acid added to bezafibrate therapy may produce significant elevations in HDL cholesterol in the range of $40-50 \%$ change. Although these low doses did produce intermittent episodes of skin flushing, they should be better tolerated than the accustomed dosage of 2-3 g per day. Other side effects such as gastrointestinal or hepatic malfunction also may be minimized with this low dose.

Table I General data on 173 patients in nicotinic acid-bezafibrate study

\begin{tabular}{|c|c|c|c|c|}
\hline Group & Control & Nicotinic acid & Bezafibrate & $N+B$ \\
\hline $\begin{array}{l}n \\
\text { Age (years) } \\
\text { Male } \\
\text { Dose/day }(\mathrm{mg} \pm \text { s.d.) }\end{array}$ & $\begin{array}{c}53 \\
62 \pm \frac{8}{37}\end{array}$ & $\begin{array}{c}37 \\
61 \pm 7 \\
31 \\
435 \pm 350\end{array}$ & $\begin{array}{c}58 \\
61 \pm 8 \\
32 \\
476 \pm 123\end{array}$ & $\begin{array}{c}25 \\
60 \pm 8 \\
19 \\
N-435 \pm 326 \\
B-512 \pm 130\end{array}$ \\
\hline $\begin{array}{l}\text { Interval I ( } 0-6 \text { month } \\
\text { No. of patients } \\
\text { Mean follow-up } \\
\text { (months) }\end{array}$ & $\begin{array}{l}22 \\
3.5 \pm 1.7\end{array}$ & $\begin{array}{c}29 \\
3.6 \pm 1.3\end{array}$ & $\begin{array}{c}43 \\
3.9 \pm 1.1\end{array}$ & $\begin{array}{c}20 \\
3.5 \pm 1.0\end{array}$ \\
\hline $\begin{array}{l}\text { Interval II (6-12 mon } \\
\text { No. of patients } \\
\text { Mean follow-up } \\
\text { (months) }\end{array}$ & $\begin{array}{l}\text { hs) } \\
29 \\
9.8 \pm 1.7\end{array}$ & $\begin{array}{c}15 \\
9.5 \pm 1.3\end{array}$ & $\begin{array}{c}24 \\
9.6 \pm 1.3\end{array}$ & $\begin{array}{c}16 \\
9.9 \pm 1.2\end{array}$ \\
\hline $\begin{array}{l}\text { Interval III ( }>12 \text { mo } \\
\text { No. of patients } \\
\text { Mean follow-up } \\
\text { (months) }\end{array}$ & $\begin{array}{l}\text { ths) } \\
25 \\
19 \pm 5\end{array}$ & $\begin{array}{c}16 \\
21 \pm 8\end{array}$ & $\begin{array}{c}24 \\
19 \pm 5\end{array}$ & $\begin{array}{c}9 \\
17 \pm 9\end{array}$ \\
\hline
\end{tabular}

Values expressed as mean \pm s.d. $\mathbf{N}=$ nicotinic acid; $\mathbf{B}=$ bezafibrate. 
Table II Changes in lipid concentrations by treatment and time

\begin{tabular}{|c|c|c|c|c|}
\hline & \multicolumn{4}{|c|}{ Months of treatment } \\
\hline & 0 & $0-6$ & $6-12$ & $>12$ \\
\hline \multicolumn{5}{|c|}{ Total cholesterol (mmol/l) } \\
\hline Control & $5.80 \pm 0.80$ & $5.78 \pm 0.80$ & $5.73 \pm 0.85$ & $5.78 \pm 0.80$ \\
\hline Nicotinic acid & $5.41 \pm 0.83$ & $5.26 \pm 0.70$ & $5.34 \pm 0.88$ & $5.31 \pm 0.73$ \\
\hline Bezafibrate & $6.71 \pm 0.80$ & $5.78 \pm 0.73^{*}$ & $5.80 \pm 0.52^{*}$ & $5.78 \pm 0.73^{*}$ \\
\hline $\mathbf{N}+\mathbf{B}$ & $6.71 \pm 1.19$ & $5.67 \pm 0.21 \dagger$ & $5.78 \pm 0.73 \ddagger$ & $5.52 \pm 0.70$ \\
\hline \multicolumn{5}{|c|}{ HDL cholesterol (mmol/l) } \\
\hline Control & $1.06 \pm 0.26$ & $0.96 \pm 0.18$ & $1.09 \pm 0.21$ & $1.09 \pm 0.23$ \\
\hline Nicotinic acid & $0.88 \pm 0.18$ & $1.11 \pm 0.18^{*}$ & $1.09 \pm 0.21^{*}$ & $1.06 \pm 0.23^{*}$ \\
\hline Bezafibrate & $1.11 \pm 0.26$ & $1.27 \pm 0.31^{*}$ & $1.37 \pm 0.28 \dagger$ & $1.32 \pm 0.36 \dagger$ \\
\hline $\mathbf{N}+\mathbf{B}$ & $0.91 \pm 0.26$ & $1.22 \pm 0.34^{*}$ & $1.30 \pm 0.39^{*}$ & $1.24 \pm 0.23 \dagger$ \\
\hline \multicolumn{5}{|c|}{ Triglycerides (mmol/l) } \\
\hline Control & $1.88 \pm 0.85$ & $1.88 \pm 0.77$ & $1.62 \pm 0.77$ & $1.62 \pm 0.62$ \\
\hline Nicotinic acid & $1.91 \pm 0.97$ & $1.64 \pm 0.54$ & $1.81 \pm 0.53$ & $1.73 \pm 0.78$ \\
\hline Bezafibrate & $2.21 \pm 1.19$ & $1.43 \pm 0.64^{*}$ & $1.45 \pm 0.63 \dagger$ & $1.41 \pm 0.51^{*}$ \\
\hline $\mathbf{N}+\mathbf{B}$ & $2.41 \pm 1.06$ & $1.63 \pm 0.56^{*}$ & $1.38 \pm 0.41 \dagger$ & $1.39 \pm 0.35 \ddagger$ \\
\hline \multicolumn{5}{|c|}{ Total/HDL cholesterol (mmol/l) } \\
\hline Control & $5.8 \pm 1.7$ & $6.2 \pm 1.1$ & $5.5 \pm 1.4$ & $5.5 \pm 1.3$ \\
\hline Nicotinic acid & $6.4 \pm 1.6$ & $4.9 \pm 1.0^{*}$ & $5.1 \pm 1.1 \dagger$ & $5.3 \pm 1.5 \dagger$ \\
\hline Bezafibrate & $6.4 \pm 1.7$ & $4.8 \pm 1.5^{*}$ & $4.4 \pm 1.0^{*}$ & $4.7 \pm 1.5^{*}$ \\
\hline $\mathrm{N}+\mathrm{B}$ & $7.9 \pm 2.7$ & $4.9 \pm 1.6^{*}$ & $4.9 \pm 1.9^{*}$ & $4.7 \pm 1.3 \dagger$ \\
\hline
\end{tabular}

Values expressed as mean \pm s.d. $\mathrm{HDL}=$ high-density lipoprotein; $\mathrm{N}=$ nicotinic acid; $\mathrm{B}=$ bezafibrate. Compared to baseline ${ }^{*} P<0.001 ; \uparrow P<0.01 ; \ddagger P<0.02$.
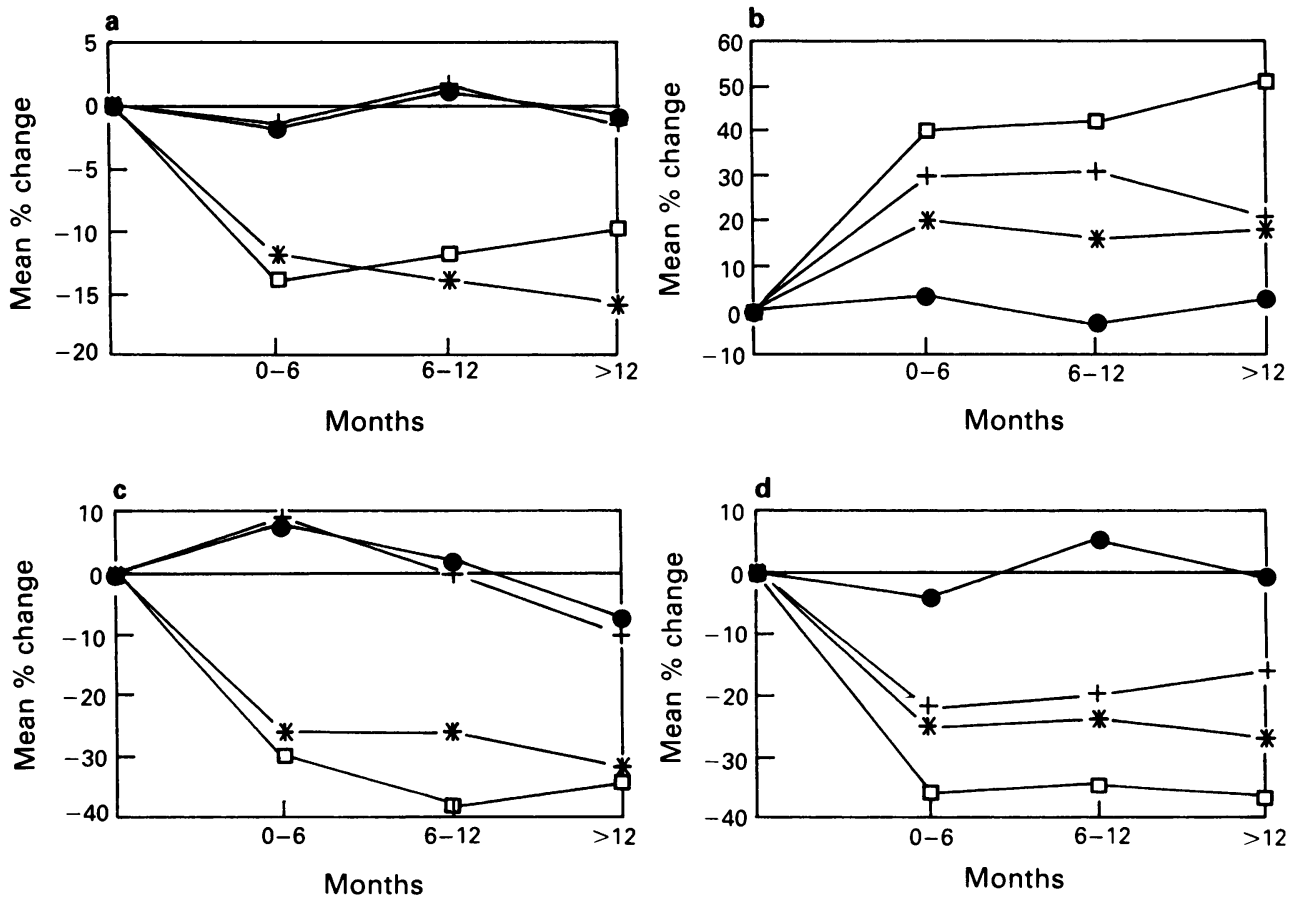

Figure 1 Mean percentage changes in lipids by treatment and time: (a) cholesterol; (b) HDL cholesterol; (c) triglycerides; (d) total cholesterol/HDL. $\mathrm{HDL}=$ high-density lipoprotein; $\mathbf{N}=$ nicotinic acid; $\mathbf{B}=$ bezafibrate $-\mathrm{O}=$ control; $+-+=\mathrm{N} ; *-*=\mathrm{B} ; \mathrm{\square}-\mathrm{\square}=\mathrm{N}+\mathrm{B}$. 
The hypocholesterolaemic effect of nicotinic acid was first demonstrated by Altschul et al. in 1955. ${ }^{12}$ In doses of 2-3 g/day, nicotinic acid not only lowers total cholesterol but also significantly elevates HDL cholesterol. ${ }^{13-15}$ We have also demonstrated that in doses of $1 \mathrm{~g} /$ day, nicotinic acid has no effect on total cholesterol level but continues to elevate HDL cholesterol. ${ }^{7}$ As a consequence of this dose-dependent action, Keenan et al. ${ }^{16}$ have indicated that low-dose nicotinic acid may be utilized for the treatment of isolated low HDL cholesterol. The present study further extends these latter results to even lower doses of nicotinic acid; the minimal effective level for HDL reduction, at least as observed in the present study, being in the range of $200-300 \mathrm{mg} /$ day.

The variety of influences of nicotinic acid ${ }^{17-19}$ and bezafibrate ${ }^{20,21}$ on HDL cholesterol metabolism of both agents has not been fully identified but additive actions may result. Analysis of the present study to determine additive or perhaps even synergistic actions, however, is complicated by the use of dissimilar groups of patients. For example, initial HDL cholesterol values were higher in the group treated with bezafibrate. The present study is also potentially limited since it does not contain the usual features of placebo control, cross-over and blinding. Nevertheless, this preliminary experience does suggest that a clinical approach exists for the vexing problem of side effects which have limited the use of nicotinic acid in a large number of patients. This consists of the administration of low-dose nicotinic acid either alone or in combination with bezafibrate. Although further, more rigorous inquiry is required, our results indicate that significant elevation in HDL cholesterol may be anticipated.

\section{References}

1. Miller, G.J. \& Miller, N.E. Plasma-high-density-lipoprotein concentration and development of ischaemic heart disease. Lancet 1975, i: 16-19.

2. Miller, N.E., Forde, O.H., Thelle, D.S. \& Mjos, O.D. The Tromso Heart Study: high-density lipoprotein and coronary heart disease: a prospective case-control study. Lancet 1977 , i: 965-970.

3. Goldbourt, U. \& Medalie, J.H. High density lipoprotein cholesterol and incidence of coronary heart disease: the Israeli Ischemic Heart Disease Study. Am J Epidemiol 1979, 109: 296-308.

4. Gordon, D.J., Probstfield, J.L., Garrison, R.J. et al. High density lipoprotein cholesterol and cardiovascular disease. Four prospective American studies. Circulation 1989, 79: 8-15.

5. Luria, M.H. Atherosclerosis: the importance of HDL cholesterol and prostacyclin: a role for niacin therapy. $\mathrm{Med}$ Hypotheses 1990, 32: 21-28.

6. Jacobs, D.R., Mebane, I.L., Bangdirvala, S.I. et al. High density lipoprotein cholesterol as a predictor of cardiovascular disease mortality in men and women: the follow-up study of the Lipid Research Clinic Prevalence Study. Am J Epidemiol 1990, 131: 32-47.

7. Luria, M.H. Effect of low-dose niacin on high-density lipoprotein cholesterol and total cholesterol/high-density lipoprotein cholesterol ratio. Arch Intern Med 1988, 148: 2493-2495.

8. Olsson, A.G., Lang, P.D. \& Vollmar, J. Effect of bezafibrate during 4.5 years of treatment of hyperlipoproteinemia. Atherosclerosis 1985, 55: 195-203.

9. Manninen, V., Elo, M.O., Frick, M.H. et al. Lipid alterations and decline in the incidence of coronary heart disease in the Helsinki Heart Study. JAMA 1988, 260, 641-651.

10. Weiner, M. \& van Eys, J. Nicotinic Acid: Nutrient CofactorDrug. New York, Marcel Dekker Inc., 1983.

11. Luria, M.H., Erel, J., Sapoznikov, D. \& Gotsman, M.S. Cardiovascular risk factor clustering and ratio of total cholesterol to high-density lipoprotein cholesterol in angiographically documented coronary artery disease. Am J Cardiol 1991, 67: 31-36.
12. Altschul, R., Hoffer, A. \& Stephen, J.D. Influence of nicotinic acid on serum cholesterol in man. Arch Biochem Biophys 1955, 54: 558-559.

13. Alderman, J.D., Pasternak, R.C., Sacks, F.M., Smith, H.S., Monrad, E.S. \& Grossman, W. Effect of a modified, welltolerated niacin regimen on serum total cholesterol, high density lipoprotein cholesterol and the cholesterol to high density lipoprotein ratio. Am J Cardiol 1989, 64: 725-729.

14. Henkin, Y., Oberman, A., Hurst, D.C. \& Segrest, J.P. Niacin revisited: clinical observations on an important but underutilized drug. Am J Med 1991, 91: 239-246.

15. Keenan, J.M., Fontaine, P.L., Wenz, J.B., Myers, S., Huang, Z. \& Ripsin, C.M. Niacin revisited: a randomized controlled trial of wax-matrix sustained-release niacin in hypercholesterolemia. Arch Intern Med 1991, 151: 1424-1432.

16. Keenan, J.M., Wenz, J.B., Ripson, C.M., Huang, Z. \& McCaffrey, D.J. A clinical trial of oat bran and niacin in the treatment of hyperlipidemia. J Family Pract 1992, 34: 313-319.

17. Packard, C.J., Stewart, J.M., Third, J.L.H.C., Morgan, H.G., Lawrie, T.D.V. \& Shepherd, J. Effects of nicotinic acid therapy on high-density lipoprotein metabolism in type II and type IV hyperlipoproteinemia. Biochem Biophys Acta 1980, 618: 53-62.

18. Knopp, R.H., Ginsberg, J., Albers, J.J. et al. Contrasting effects of unmodified and time-release forms of niacin on lipoproteins in hyperlipidemic subjects: clues to mechanisms of action of niacin. Metabolism 1985, 34: 642-650.

19. Johansson, J. \& Carlson, L.A. The effects of nicotinic acid treatment on high density lipoprotein particle size subclass levels in hyperlipidaemic subjects. Atherosclerosis 1990, 83: 207-216.

20. Gavish, D., Oschry, Y., Fainaru, M. \& Eisenberg, S. Change in very low-, low-, and high density lipoproteins during lipid lowering (bezafibrate) therapy: studies in type IIA and type IIB hyperlipoproteinaemia. Eur J Clin Invest 1986, 16: 61 - 68.

21. Series, J.J., Caslake, M.J., Kilday, C. et al. Effect of combined therapy with bezafibrate and cholestyramine on low-density lipoprotein metabolism in type IIa hypercholesterolemia. Metabolism 1989, 38: 153-158. 